\title{
SUMMARY OF PERSONAL NEUTRON DOSEMETER RESULTS OBTAINED WITHIN THE EVIDOS PROJECT
}

M. Luszik-Bhadra ${ }^{1, *}$, T. Bolognese-Milsztajn ${ }^{2}$, M. Boschung ${ }^{3}$, M. Coeck ${ }^{4}$, G. Curzio ${ }^{5}$, D. Derdau ${ }^{8}$, F. d'Errico ${ }^{5}$, A. Fiechtner ${ }^{3}$, J.-E. Kyllönen ${ }^{6}$, V. Lacoste ${ }^{2}$, B. Lievens ${ }^{9}$, L. Lindborg ${ }^{6}$, A. Lovefors Daun ${ }^{10}$, M. Reginatto ${ }^{1}$, H. Schuhmacher ${ }^{1}$, R. Tanner ${ }^{7}$ and F. Vanhavere ${ }^{4}$

${ }^{1}$ Physikalisch-Technische Bundesanstalt, D-38116 Braunschweig, Germany

${ }^{2}$ Institut de Radioprotection et de Sûreté Nucléaire, F-92265 Fontenay-aux-Roses, France

${ }^{3}$ Paul Scherrer Institut, CH-5232 Villigen, Switzerland

${ }^{4}$ Studiecentrum voor Kernenergie - Centre d'étude de l'énergie nucléaire, B-2400 Mol, Belgium

${ }^{5}$ Dipartimento di Ingegneria Meccanica, Nucleare e della Produzione, I-56126 Pisa, Italy

${ }^{6}$ Swedish Radiation Protection Authority, SE-171-16 Stockholm, Sweden

${ }^{7}$ Radiation Protection Division, Health Protection Agency, Chilton, Didcot OX11 0RQ, UK

${ }^{8}$ Kernkraftwerk Krümmel GmbH, Elbuferstrasse 82, 21496 Geesthacht, Germany

${ }^{9}$ Belgonucléaire, B-2480 Dessel, Belgium

${ }^{10}$ Ringhals NPP, SE-430 22 Väröbacka, Sweden

Within the EC project EVIDOS ('Evaluation of Individual Dosimetry in Mixed Neutron and Photon Radiation Fields'), different types of active neutron personal dosemeters (and some passive ones) were tested in workplace fields at nuclear installations in Europe. The results of the measurements which have been performed up to now are summarised and compared to our currently best estimates of the personal dose equivalent $H_{\mathrm{p}}(\mathbf{1 0})$. Under- and over-readings by more than a factor of two for the same dosemeter in different workplace fields indicate that in most cases the use of field-specific correction factors is required.

\section{INTRODUCTION}

Neutron dosemeters used for the determination of the personal dose equivalent for neutrons in mixed neutron/photon fields are much less precise than those for photons. Usually readings are accepted which are lower or higher than the conventional true value up to a factor two. Passive dosemeters are used with fieldspecific correction factors and have dose detection thresholds in the order of $0.1-0.5 \mathrm{mSv}$. Active neutron personal dosemeters are used rather infrequently still in workplaces and have become available only during the past few years. Both types were tested in workplace fields within the EVIDOS project, and their readings are compared to estimates of the personal dose equivalent $H_{\mathrm{p}}(10)$ which have been determined in the same fields by spectrometry.

\section{DOSEMETERS USED}

The personal dosemeters used in the EVIDOS project and their main characteristics are listed together with the HpSLAB, an instrument which uses a superheated drop detector at $10 \mathrm{~mm}$ depth in a slab phantom and which is expected to have a small energy dependence and thus may be developed into a reference instrument for $H_{\mathrm{p}}(10)$, in Table 1 .

The electronic personal dosemeters used are the few devices which have been commercially available

${ }^{*}$ Corresponding author: marlies.luszik-bhadra@ptb.de in the past few years (Thermo Electron EPD-N, Aloka PDM-313). They are dosemeters from first industrial prototype series (Thermo Electron EPD-N2, Saphydose-n) and laboratory prototypes which were in the stage of light-weight battery-operated instruments (PTB DOS-2002, DMC2000GN). In addition, dosemeters with (almost) immediate readout (BTI bubble detectors, Rados DISN) were used as well as passive dosemeters (nuclear track detectors from PSI and NRPB) and the TLD dosemeters of the facilities visited (Nuclear power plants Krümmel, Ringhals).

\section{DOSEMETER READINGS IN WORKPLACE FIELDS}

The dosemeters were irradiated in:

- two simulated workplace fields in Cadarache, France (SIGMA and CANEL),

- four workplace fields in Krümmel, Germany (two at the BWR: KKK Reactor top, KKK SAR, two at a cask: KKK Cask midline and KKK Cask side),

- two workplace fields at the Venus research reactor in Mol, Belgium (Venus control room, Venus reactor side),

- four workplace fields at the fuel facility Belgonucléaire in Mol, Belgium (Belgo P.1 Bare rods, Belgo P.2A Unshielded rack, Belgo P.2B Shielded rack, Belgo P.3 Stockroom) and in 


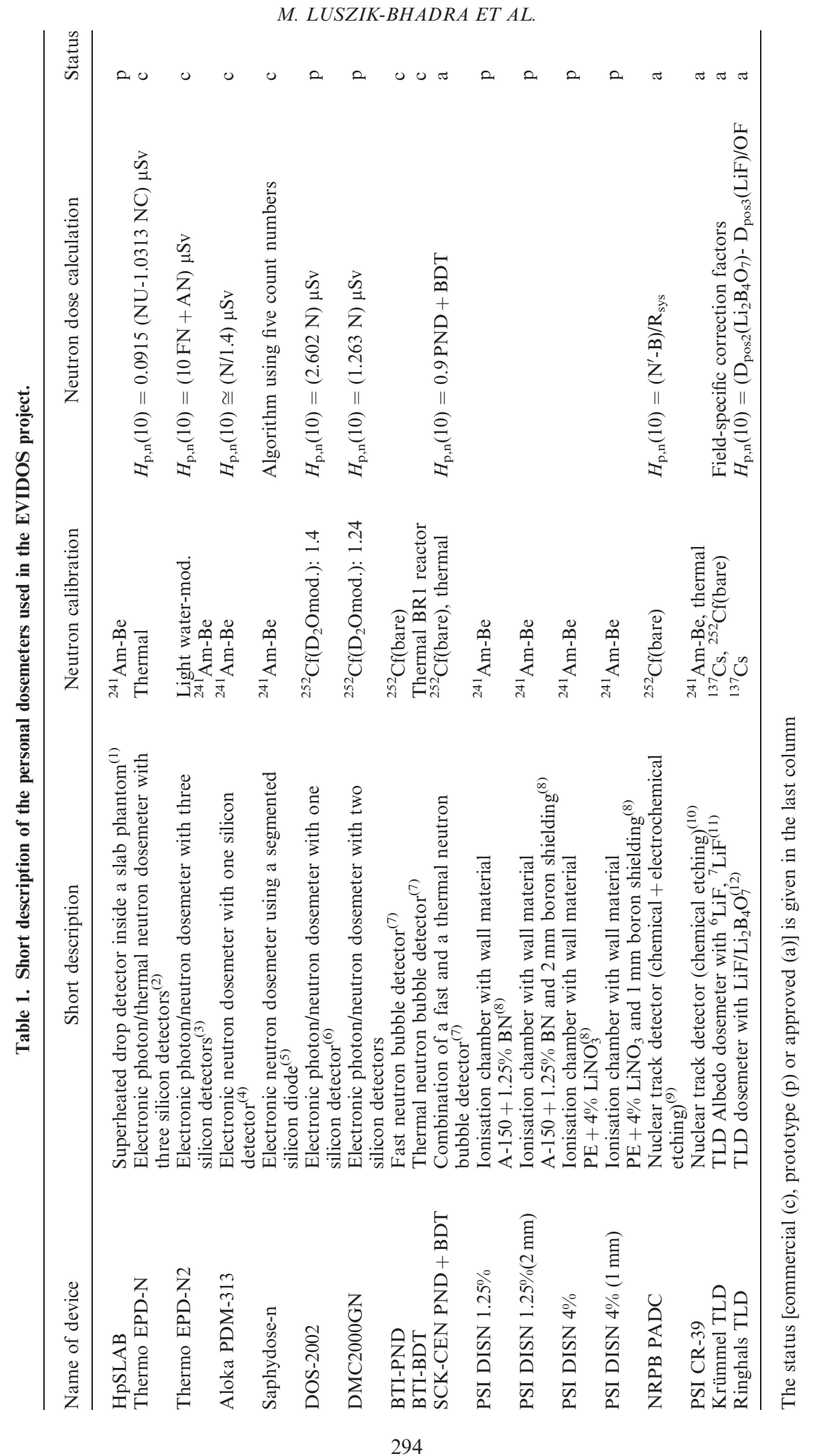


- four workplace fields in Ringhals, Sweden (two at the PWR Ringhals, Block 4: Pos L Entrance lock and Pos A Containment and two at a transport cask with used fuel: Pos D Cask midline, Pos N Cask end).

The criteria for selecting these fields were:

- Neutrons contribute with at least $20 \%$ to the ambient dose equivalent.

- The places are typical workplaces which are regularly visited for special jobs.

A more detailed description of the workplace fields is given in Refs ${ }^{(13-15)}$.

The dosemeters were attached to the front and back side of an ISO phantom $(30 \times 30 \times 15 \mathrm{~cm})$, with the reference point at the front surface. The front surface was usually directed towards the source (reactor, cask and fuel elements), with the exception of a position below the reactor in Krümmel where the front was directed towards the lock while the main source was above. The dosemeters were attached on the phantom in such a way that their active parts stayed in an area of $20 \times 20 \mathrm{~cm}$ and the boron shielding of the neighbouring dosemeters were at least $5 \mathrm{~cm}$ apart. Some passive dosemeters (chiefly track detectors) were also mounted on the phantom sides and for more sensitive devices (HpSLAB and bubble detectors), additional irradiations at an angle of $45^{\circ}$ right, $45^{\circ}$ left, $45^{\circ}$ up, $45^{\circ}$ down were performed.

The results of the measurements for front direction are summarised in Table 2. The measured dose equivalent rates are given with one standard uncertainty containing the statistical uncertainties, the uncertainties introduced by the calibration procedures and - in case of the passive dosemeters - the uncertainties introduced by background subtractions. Since there was no time for repeated measurements, the statistical uncertainties were estimated from count numbers (when available) and experience. The uncertainties introduced by the calibration procedures were estimated in most cases in the order of 5-6\% with exception of bubble detectors with uncertainties upto $20 \%$ for thermal neutron devices. Thus, high uncertainties as given for several measurement results are chiefly a result of small count numbers due to the limited time available for all measurements performed within the project. Our best estimates of the personal dose equivalent rate $\dot{H}_{\mathrm{p}, \mathrm{DS}}(10)$ (to which these results are compared) are those resulting from spectrometry measurements using the PTB directional spectrometer with silicon diodes (DS) ${ }^{(15)}$. As long as not all possible data available from other measurements are consistently interpreted, these values are only preliminary. A high uncertainty of $30 \%$ is assigned at the moment. $\dot{H}_{\mathrm{p}, \mathrm{DS}}(10)$ values which are considerably smaller (up to a factor of four, see Table 2) than the reference values of the ambient dose equivalent rate $\dot{H}^{*}(10)$ indicate fields where neutrons do not chiefly impinge from the front. Both values- $\dot{H}_{\mathrm{p}, \mathrm{DS}}(10)$ and $\dot{H}^{*}(10)$ - are given in the first columns of Table 2. In addition, the workplace field is characterised by the ratio of neutron-to-photon dose equivalent rates $\dot{H}_{\mathrm{n}}^{*}(10) / \dot{H}_{\gamma}^{*}(10)$, using the photon dose equivalent rate reading of a FHT $191 \mathrm{~N}$ ionisation chamber calibrated with ${ }^{60} \mathrm{Co}$.

\section{DOSEMETER RESPONSES IN WORKPLACE FIELDS}

The dosemeter response, i.e., the measured value divided by the reference value, is shown for some selected dosemeters in Figure 1. The lowest spread of the results (but still a factor of 2-3) is obtained for the dosemeters which are based on the superheated drop detectors HpSLAB ${ }^{(1)}$ and SCK-CEN PND + $B \mathrm{DT}^{(7)}$ and for those based on the nuclear track detectors NRPB PADC ${ }^{(9)}$. The HpSLAB and the SCK-CEN PND + BD $\mathrm{T}$ indicate mean values which are by a factor of 1.4 and a factor 1.8 higher and the NRPB PADC indicates mean values which are lower (factor 0.9) than the reference values $\dot{H}_{\mathrm{p}, \mathrm{DS}}(10)$ obtained from spectrometry.

The response of the electronic dosemeters (Thermo EPD-N2, Saphydose-n, PTB DOS-2002) varies by about a factor of ten. The ALOKA dosemeter shows a spread of response of two orders of magnitude. It overreads at reactors by up to a factor of 60 .

The DISN 4\% device is the favoured one among the devices with different wall material and shieldings ${ }^{(8)}$. Although its neutron response is comparable to - or even better than-those of the electronic devices, its main drawback is that a photon reading has to be subtracted. This, in fields with a high photon dose contribution (KKK SAR, see Table 1), resulted in zero readings. The DISN $1.25 \%$ devices were in most measurements used on the backside of the phantom.

The dosemeters which chiefly indicate thermal and epithermal neutrons (Thermo EPD-N and BTI-BDT) showed responses below unity. The response of the EPD-N was in all workplace fields (with the exception of SIGMA) lower than 0.3 , indicating small dose contributions of thermal neutrons in these fields. The BTI-BTD in general showed higher response values than the EPD-N (0.99 for Ringhals Pos A Containment, see values in Table 1).

In general, the response values observed in reactor fields (full symbols in Figure 1) are higher than those found in fields at the transport casks and at the MOX fuel factory (open symbols in Figure 1). This allows a field-specific correction factor to be used for a special class of workplace fields. This can be done 
M. LUSZIK-BHADRA ET AL.

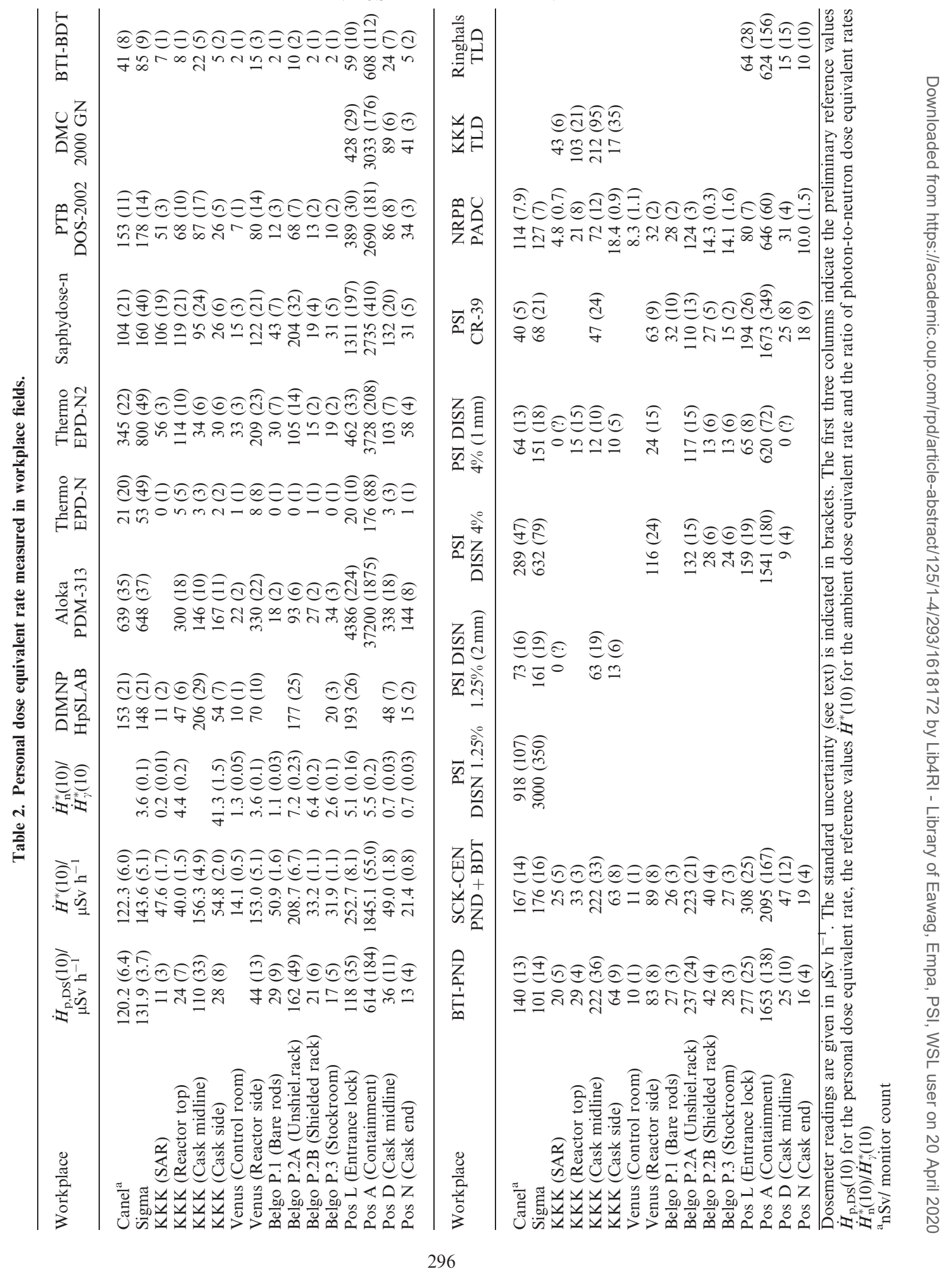




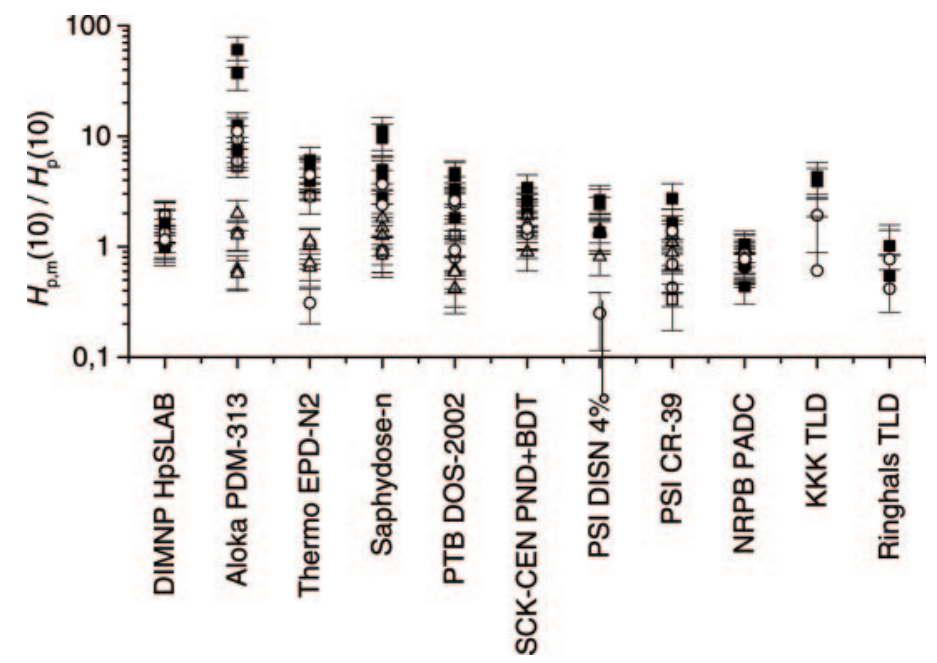

Figure 1. Response of different personal dosemeters in the simulated workplace field CANEL ( $\square$ ), the reactor fields ( $\square$ ), the fields at transport casks $(\bigcirc)$ and the fields at the fuel facility Belgonucléaire $(\triangle)$.

Table 3. Mean correction factor for reactor fields.

\begin{tabular}{lc}
\hline Device & $\begin{array}{c}\text { Field-specific } \\
\text { correction factor }\end{array}$ \\
\hline DIMNP HpSLAB & 0.64 \\
Aloka PDM-313 & 0.034 \\
Thermo EPD-N2 & 0.20 \\
Saphydose-n & 0.15 \\
PTB DOS-2002 & 0.29 \\
DMC 2000GN & 0.23 \\
SCK-CEN PND + BDT & 0.43 \\
PSI DISN 4\% & 0.46 \\
PSI CR-39 & 0.52 \\
NRPB PADC & 1.32 \\
KKK TLD & 0.24 \\
Ringhals TLD & 1.28 \\
\hline
\end{tabular}

either by using the calibration as indicated in Table 1 and the results of this campaign (see Tables 2 and 3 for reactor fields) or by using a more appropriate calibration field. In the case of the EPD-N2, a calibration using the simulated workplace field CANEL will give improved readings at reactor fields, whereas this is not the case for the dosemeters Saphydose- $\mathrm{n}^{(5)}$ and DOS-2002 which show responses that are close to unity at CANEL and, despite this fact, responses in reactor fields that are too high (see the values in Table 2).

In general, no trend of higher or lower response values depending on the photon contribution in the fields (see Table 1) was observed.

The HpSLAB device indicates our preliminary best estimate of $H_{\mathrm{p}}(10)$ as obtained from spectrometry within a factor of $0.7-1.3$, if the readings are adjusted by dividing them by 1.4. It may be therefore suited as a reference instrument, if recently performed calculations $^{(1)}$ of the response matrix of this system are fully analysed.

\section{LOCAL DEVICES}

As TLD dosemeters usually require field-specific correction factors which depend on the dosemeter itself and on the characteristics of the fields, only the local devices as used in the facilities visited were used.

The albedo dosemeters at Krümmel were evaluated by means of calibration factors which for the measurements at the cask were by a factor of two higher than inside the reactor. The high uncertainties at the cask (see Figure 1) result from short irradiations of only $\sim 2 \mathrm{~h}$.

The dosemeters at Ringhals are usually used with field-specific correction factors. Three different overresponse factors (OF, see Table 1), depending on where the person has been working, are used. These factors have been determined using knowledge from earlier spectrometric investigations of the workplaces at Ringhals ${ }^{(12)}$. Although the dosemeter uses no albedo shielding and chiefly detects thermal and epithermal neutrons, the spread of the measured responses is acceptable and the mean response close to unity. The results of the campaign will be used to improve the field-dependent correction factors.

The local dosemeters used at Belgonucléaire and at the VENUS reactor for routine personnel monitoring are the BTI-PND and the SCK-CEN PND + BDT bubble detectors [see Ref. ${ }^{(7)}$ for a more detailed analysis]. 
M. LUSZIK-BHADRA ET AL.

Table 4. Predicted and measured dose rates for the PTB DOS-2002.

\begin{tabular}{lccc}
\hline Workplace & $\dot{H}_{\text {p,pred. }}(10) / \mu \mathrm{Sv} \mathrm{h}^{-1}$ & $\dot{H}_{\mathrm{p}, \mathrm{m}}(10) / \mu \mathrm{Sv} \mathrm{h}$ & $\dot{H}_{\mathrm{p}, \mathrm{pred} .}(10) / \dot{H}_{\mathrm{p}, \mathrm{m}}(10)$ \\
\hline KKK (SAR) & $40(20)$ & $51(3)$ & $0.78(39)$ \\
KKK (Reactor top) & $51(25)$ & $68(10)$ & $0.75(38)$ \\
KKK (Cask midline) & $47(25)$ & $87(17)$ & $0.54(27)$ \\
KKK (Cask side) & $14(7)$ & $26(5)$ & $0.54(27)$ \\
Venus (Reactor side) & $55(27)$ & $80(14)$ & $0.68(34)$ \\
Belgo P.1 (Bare rods) & $14(7)$ & $12(3)$ & $1.12(56)$ \\
Belgo P.2A (Unshielded rack) & $77(39)$ & $68(7)$ & $1.13(56)$ \\
Belgo P.2B (Shielded rack) & $11(5)$ & $13(2)$ & $0.83(42)$ \\
Belgo P.3 (Stockroom) & $9(5)$ & $389(30)$ & $0.95(47)$ \\
Pos L (Entrance lock) & $430(215)$ & $2690(181)$ & $1.10(55)$ \\
Pos A (Containment) & $1835(918)$ & $86(8)$ & $0.68(34)$ \\
Pos D (Cask midline) & $50(25)$ & $34(3)$ & $0.58(29)$ \\
Pos N (Cask end) & $24(12)$ & & $0.71(35)$ \\
\hline
\end{tabular}

The uncertainties stated correspond to one standard deviation

\section{COMPARISON WITH THE PREDICTED RESPONSE}

The high deviations of the readings from $H_{\mathrm{p}}(10)$ in workplaces can be explained by the monoenergetic response functions of the dosemeters which are not ideal. A first estimate of the response in workplace fields has been obtained for the dosemeter PTB DOS-2002 by folding the response of the dosemeter [as a function of energy and angle, see Ref. ${ }^{(16)}$ ] by the direction-dependent neutron spectra having been obtained within the project [see Ref. ${ }^{(15)}$ ].

By folding this response matrix with the directiondependent neutron spectra, predicted readings were obtained. Since the integral dose values obtained from the directional spectrometer already have uncertainties of about $30 \%{ }^{(15)}$ and additional uncertainties add to these in determining the dosemeter response, the values obtained have an estimated uncertainty of about $50 \%$. In Table 4 , the results of the predicted dose rates are compared with the measured dose rates for the investigated workplace fields. The agreement is satisfactory within the uncertainties estimated. The high over-readings observed in the reactor fields are a result of high dosemeter overresponses for intermediate energy neutrons and an appreciable contribution of these neutrons in the fields.

\section{UNCERTAINTIES}

As the time available for all experiments was limited, some dosemeters could be irradiated for a short period of time only $(\sim 1 \mathrm{~h})$, in other cases (especially for the passive devices) irradiations were performed overnight and the uncertainties of the dose rate values indicated in Table 2 do not allow the low dose limits of the dosemeters to be compared.
The statistical uncertainties can, however, be estimated quite easily from the algorithms given in Table 1. For a personal dose equivalent reading of $100 \mu \mathrm{Sv}$, the relative uncertainty ( $1 \mathrm{SD}$ ) is $8.4 \%$ for Aloka PDM-313, 16.1\% for PTB DOS-2002 and $11.4 \%$ for DMC2000GN.

In the case of the Thermo EPD-N2, the readings depend on two count numbers: one (FN) corresponds to a fast neutron reading, the other one (AN) to an albedo neutron reading. Since in most of the workplace fields these readings were also determined, the relative uncertainty for a measured personal dose equivalent of $100 \mu \mathrm{Sv}$ has been determined for the different workplace fields. At the transport casks and reactors, it is in the order of $10-20 \%$, whereas for the fields with unshielded MOX fuel, it is higher (up to $29 \%$ ).

In reactor fields, the readings of $100 \mu \mathrm{Sv}$ correspond - with appropriate correction factors - to personal dose equivalent values of about $20 \mu \mathrm{Sv}$ (see Table 3). Hence, in reactor fields, the personal dose equivalent of $20 \mu \mathrm{Sv}$ can be determined with a low standard deviation of about $10 \%$.

\section{TECHNICAL PERFORMANCE}

Most of the devices were used without problems. In the case of the laboratory type device PTB DOS-2002 care had to be taken as the instrument was still shock-sensitive. The DISN devices could not be used in fields with a high photon dose contribution.

\section{CONCLUSION}

For the determination of the neutron dose equivalent, the electronic personal dosemeters still require field-specific correction factors. The measurements 
performed within the EVIDOS project in 14 real workplace fields and two simulated ones reveal that mean correction factors can be used for some classes of workplace fields, such as reactors, transport casks and MOX fuel. In reactor fields, most of the electronic dosemeters overrespond by more than a factor of 3. The measured readings have been compared with predictions and yielded reasonable agreement. The electronic dosemeters indicate a personal dose equivalent of about $20 \mu \mathrm{Sv}$ in reactor fields with a standard uncertainty of about $10 \%$.

\section{ACKNOWLEDGEMENTS}

The authors wish to express their gratitude to the staffs at Cadarache, Krümmel, Mol and Ringhals who helped during the campaigns. This research is partly funded by the European Commission under the auspices of the Euratom $5^{\text {th }}$ Framework Programme: Nuclear Energy, 1998-2002, Contract No: FIKR-CT-2001-00175.

\section{REFERENCES}

1. d'Errico, F., Giusti, V. and Siebert, B. R. L. A new neutron monitor and extended conversion coefficients for $H_{p}(10)$. This workshop.

2. Siemens Plc. 2000: Neutron sensitive electronic personal dosemeter (EPD-N Mk2.0), in Technical Handbook (2000).

3. Siemens Plc. 2002: Electronic personal dosemeter for neutrons and photons EPD- $N^{2}$, in Technical Handbook (2002).

4. Luszik-Bhadra, M. and Rimpler, A. Stand und Perspektiven elektronischer Personendosimeter für Neutronen/Photonenstrahlungsfelder. Contribution to FS Jahrestagung, Kloster Seeon, Germany, April 21-25 (TÜV-Verlag) (2002).

5. Chau, Q. and Lahaye, T. Evaluation of dose equivalent by the electronic personal dosemeter for neutron
"Saphydose- $N$ " at different workplaces of nuclear facilities. This workshop.

6. Luszik-Bhadra, M., Wendt, W. and Weierganz, M. The electronic neutron/photon dosemeter PTB DOS2002. Radiat. Prot. Dosim. 110, 291-295 (2004).

7. Vanhavere, F., Coek, M. and Lievens, B. The response of the BTI bubble detectors in mixed gamma-neutron workplace fields. This workshop.

8. Boschung, M., Fiechtner, A. and Wernli, C. Performance of a personal neutron dosemeter based on direct ion storage at workplace fields in the nuclear industry. This workshop.

9. Tanner, R. J., Hager, L. G. and Bartlett, D. T. Improved characterisation of the HPA PADC neutron personal dosemeter. This workshop.

10. Fiechtner, A., Boschung, M. and Wernli, C. Progress report of the CR-39 neutron personal monitoring service at PSI. This workshop.

11. Piesch, E. and Burgkhardt, B. Albedo dosimetry system for routine personnel monitoring. Radiat. Prot. Dosim. 23, 117-120 (1988).

12. Drake, P. Personal Dosimetry in mixed radiation fields, measurements in nuclear working environments. Thesis: University of Gothenburg, Department of Radiation Physics (Göteborg, Sweden) (1999).

13. d'Errico, F., Bartlett, D., Bolognese-Milsztajn, T., Boschung, M., Coeck, M., Curzio, G., Fiechtner, A., Kyllönen, J.-E., Lacoste, V., Lindborg, L. et al. Evaluation of individual dosimetry in mixed neutron and photon radiation fields (EVIDOS). Part I: Scope and methods of the project. This workshop.

14. Lacoste, V., Reginatto, M., Assélineau, B. and Muller, H. Bonner sphere neutron spectrometry at nuclear workplaces in the framework of the EVIDOS project. This workshop.

15. Luszik-Bhadra, M., Bolognese-Milsztajn, T., Boschung, M., Coeck, M., Curzio, G., d'Errico, F., Fiechtner, A., Lacoste, V., Lindborg, L., Reginatto. M., Schuhmacher, H., Tanner, R., Vanhavere, F. Direction distributions of neutrons and reference values of the personal dose equivalent in workplace fields. This workshop.

16. Reginatto, M. and Luszik-Bhadra, M. Determination of the full response function of personal neutron dosemeters. This workshop. 